\title{
Lifestyle has Significant Influence over Obesity among School Children in Bangladesh
}

\author{
BK-Rauniyar, Sharmin-Jahan, Nusrat-Sultana, Mashfiqul-Hasan, M Atiqur-Rahman, Yasmin-Aktar, M Fariduddin \\ and MA Hasanat* \\ Department of Endocrinology, Bangabandhu Sheikh Mujib Medical University (BSMMU), Bangladesh
}

Submission: December 13, 2018; Published: February 22, 2019

*Corresponding author: MA Hasanat, Professor of Endocrinology, Department of Endocrinology, Bangabandhu Sheikh Mujib Medical University (BSMMU), D-Block, Room No. 1524, Shahbag, Dhaka, Bangladesh

\section{Abstract}

Background: Childhood obesity associated with lifestyle changes poses a major public health challenge.

Objective: To assess the contributing factors of childhood obesity among school children in Dhaka, Bangladesh.

Methods: Overweight and obesity were studied in 504 school children (age: 11.31 $\pm 1.39, \mathrm{M} \pm \mathrm{SD}$; M/F: 256/248) using updated body mass index (BMI, kg/m2) reference. Socioeconomic status on basis of family income and life style factors like meals, vehicle-use, sedentary entertainments and outdoor activities were considered.

Results: Obesity was higher in children from high socioeconomic class (high vs. middle vs. low socioeconomic status: obese $22.2 \%$ vs. $11.8 \%$ vs. $3.7 \%$; $<0.001$ ). Meal frequency was statistically similar among BMI groups. About $55 \%$ of obese children used vehicle while $79.7 \%$ of underweight went by foot $(\mathrm{p}<0.001)$. Obesity and overweight were relatively higher among children spending more time in sedentary entertainment [1 hr vs. $2 \mathrm{hr}$ vs. $3 \mathrm{hr}$ vs. $4 \mathrm{hr}$ (obesity and overweight): $11.5 \%$ and $8.6 \%$ vs. $14.7 \%$ and $15.4 \%$ vs. $12.8 \%$ and $15.4 \%$ vs. $22.2 \%$ and 5.6\%] but not significant ( $\mathrm{p}=0.158$ ). Similarly, no significant difference for BMI between groups spending time with outdoor games for one hour or less or more $(\mathrm{p}=0.304)$. BMI positively correlated with socioeconomic condition $(r=0.286, p<0.001)$, sedentary entertainments ( $r=0.131$, $\mathrm{p}=0.003)$ and use of vehicles $(\mathrm{r}=0.122, \mathrm{p}=0.006)$. Socio-economic condition $(\mathrm{p}=0.007)$ and use of vehicle in going to school $(\mathrm{p}=0.005)$ were found to be independent predictors for obesity.

Conclusions: More use of vehicles for going to school and better socioeconomic status seem to be important contributing factors for childhood obesity in Bangladesh.

Keywords: Childhood obesity; Lifestyle; Obesity; Body mass index; Low-fiber foods

\section{Introduction}

Recently obesity is considered as one of the important noncommunicable medical problems that has been a concern globally. The emerging epidemics of obesity, diabetes and Cardiovascular Diseases (CVD) together constellate a phenomenon to affect subjects without regard to the ethnic origin, gender, socioeconomic status and age groups [1]. Among these entities, obesity may be easy to deal by modulation of lifestyle and food habits deserving earliest intervention because of minimum medication concern rather than extensive counseling on lifestyle modification. It is associated with an increased risk of morbidity and mortality as well as reduced life expectancy. The last two decades of the previous century have observed dramatic increase in health care costs due to obesity and related issues among children and adolescents [2].
Though adult body mass index (BMI) thresholds of 25 and 30 $\mathrm{kg} / \mathrm{m}^{2}$ is considered for overweight and obesity respectively, there is little consensus as to the best way to define this in children [2]. Children with BMI equal to or exceeding the age-gender-specific $95^{\text {th }}$ percentile are denoted as obese while those with BMI equal to or exceeding the $85^{\text {th }}$ but below $95^{\text {th }}$ percentiles are defined overweight and are at risk for obesity related co-morbidities [3].

Recent changes in civilization and socioeconomic aspects probably have coined the issue of childhood obesity worldwide. Changes in food habits attributable to urbanization is thought to promote obesity, of which frequent consumption of snacks and meals at different fast-food outlets $[4,5]$ consumption of oversized portions at home and at restaurants [6,7], consumption of high 


\section{Current Research in Diabetes \& Obesity Journal}

calorie foods, such as high-fat, low-fiber foods [8,9] and intake of sweetened beverages $[10,11]$ play important role.

Now-a-days energy dense foods have become major constituent of children meal because of its easy availability in prepared form as well as a false belief of the parents of upgrading social status by these foods. Screen time including television viewing and other sedentary activities may also be related to childhood obesity $[12,13]$. Unfortunately, these habits are growing exponentially in developing countries like Bangladesh. A low level of physical activity is definitely promoted by an automated and automobile-oriented environment that is conducive to sedentary lifestyle [14]. Lack of facilities like safe walkways, bicycle paths, adequate playgrounds and parks for children and adolescents that can help preventing obesity should be considered on priority basis in dealing the management of childhood obesity. These aspects of childhood obesity have not been studied to satisfactory extent in Bangladesh. Hence the present pilot study was designed to have insights into contributing factors of childhood obesity in primary school children in Dhaka, Bangladesh.

\section{Materials and Methods}

Study subjects and design: This cross-sectional study included 504 primary school children of 9-14 years of age and was carried out in five schools of Dhaka city corporation (DCC) by multistage random sampling from June 2014 to Jan 2016. Of the ten zones, five zones were selected on random basis. From each of these five zones one ward was selected from which a single school was finally selected. Thus, five schools were selected for the study. All students of class IV and class V of the selected schools were recruited. Same group of investigators visited each school to collect the data. All the instruments were appropriately calibrated. Information regarding the food habits and physical activity was recorded in a semi-structured questionnaire by directly interviewing the children and if necessary, their parents. Informed written consent from parents/legal guardians were obtained through the school authority. Study was approved by the institutional review board (IRB) of Bangabandhu Shekih Mujib Medical University (BSMMU).

\section{Statistical analysis}

Data were analyzed by SPSS (version 22). Results were presented as means $( \pm \mathrm{SD})$ and frequency with percentage by using reference cut-off values as appropriate. For non-parametric variables, Chi-square test was preferred. Pearson's or Spearman's correlations were used to see relationship among related variables. Influence of various factors over obesity was assessed by multiple regression analysis. $\mathrm{P} \leq 0.05$ was considered as significant.

\section{Results}

Mean age of the children was $11.3 \pm 1.39$ (year, $\mathrm{M} \pm$ SD), 256 (50.8\%) were boys and 248 (49.2\%) were girls. Among them $12.9 \%(65 / 504)$ were overweight and $10.9 \%$ (55/504) were obese (Figure 1). The BMI categories were analyzed in the light of their socioeconomic status as well as various lifestyle related factors including frequency of meals, use of vehicles, screen time and spending time in outdoor activities.

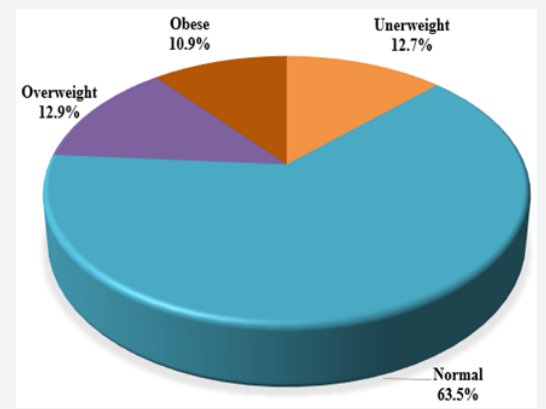

BMI calculated under reference cut-off value by Center for Disease Control $(\mathrm{CDC})$; Underweight: $\mathrm{BMI}<5^{\text {th }}$ percentile; Normal: $\mathrm{BMI} \geq 5^{\text {th }}$ to $<85^{\text {th }}$ percentile; Overweight: $\mathrm{BMI} \geq 85^{\text {th }}$ to $<$ $95^{\text {th }}$ percentile; Obese: $\mathrm{BMI} \geq 95^{\text {th }}$ percentile

Figure 1: Body mass index (BMI) categories of children ( $n=504)$

Frequency of obesity was higher in children from high socioeconomic class, whereas frequency of underweight children was more in lower socioeconomic class (high vs. middle vs. low socioeconomic status: obese $22.2 \%$ vs. $11.8 \%$ vs. $3.7 \%$; overweight $17.3 \%$ vs. $13.7 \%$ vs. $9.3 \%$; normal BMI $55.5 \%$ vs. $63.0 \%$ vs. $68.3 \%$; underweight $4.9 \%$ vs. $11.5 \%$ vs. $18.6 \%$; p<0.001; Table 1).

Table 1: BMI status in various socioeconomic groups

\begin{tabular}{|c|c|c|c|c|}
\hline BMI Status & High & Middle & Low & Total \\
\hline $\begin{array}{c}\text { Under- } \\
\text { weight }\end{array}$ & $4(4.9)$ & $30(11.5)$ & $30(18.6)$ & 64 \\
\hline Normal & $45(55.5)$ & $165(63.0)$ & $110(68.3)$ & 320 \\
\hline Overweight & $14(17.3)$ & $36(13.7)$ & $15(9.3)$ & 65 \\
\hline Obese & $18(22.2)$ & $31(11.8)$ & $6(3.7)$ & 55 \\
\hline Total & 81 & 262 & 161 & \\
\hline
\end{tabular}

(Within parenthesis are percentages over column total)

$X^{2}: 30.304 ; \mathrm{p}<0.001$; BMI: Body Mass Index; BMI calculated under reference cut-off value by Center for Disease Control (CDC); Underweight: BMI $<5^{\text {th }}$ percentile; Normal: BMI $\geq 5^{\text {th }}$ to $<85^{\text {th }}$ percentile; Overweight: $\mathrm{BMI} \geq 85^{\text {th }}$ to $<95^{\text {th }}$ percentile; Obese: $\mathrm{BMI} \geq 95^{\text {th }}$ percentile; Socioeconomic groups High: Family income > 40000 taka/month; Middle: Family income 15000-39000 taka/month; Low: Family income $<15000$ taka/month

Table 2: Relation of BMI status with frequency of meals

\begin{tabular}{|c|c|c|c|c|c|}
\hline $\begin{array}{c}\text { Meal } \\
\text { Fre- } \\
\text { quency/ } \\
\text { Day }\end{array}$ & $\begin{array}{c}\text { Under- } \\
\text { weight }\end{array}$ & Normal & $\begin{array}{c}\text { Over- } \\
\text { weight }\end{array}$ & Obese & Total \\
\hline 3 & $15(16.5)$ & $62(68.1)$ & $9(9.9)$ & $5(5.5)$ & 91 \\
\hline 4 & $28(11.7)$ & $\begin{array}{c}157 \\
(65.7)\end{array}$ & $28(11.7)$ & $26(10.9)$ & 239 \\
\hline 5 & $17(10.5)$ & $96(59.3)$ & $27(16.7)$ & $22(13.6)$ & 162 \\
\hline 6 & $4(33.3)$ & $5(41.7)$ & $1(8.3)$ & $2(16.7)$ & 12 \\
\hline Total & $64(12.7)$ & $\begin{array}{c}320 \\
(63.5)\end{array}$ & $65(12.9)$ & $55(10.9)$ & 504 \\
\hline
\end{tabular}

(Within parenthesis are percentages over row total)

$X^{2}: 14.444$; P: 0.107; Underweight: $\mathrm{BMI}<5^{\text {th }}$ percentile; Normal: BMI percentile; Normal: $\mathrm{BMI} \geq 5^{\text {th }}$ to $<85^{\text {th }}$ percentile; Overweight: $\mathrm{BMI} \geq 85^{\text {th }}$ to $<95^{\text {th }}$ percentile; Obese: $\mathrm{BMI} \geq 95^{\text {th }}$ percentile 


\section{Current Research in Diabetes \& Obesity Journal}

Table 2 depicts the frequencies of different BMI status in context to meal. Of the total 504 children, 91 (18.1\%) children had three major meals per day, 239 (47.4\%) had four major meals, $162(32.0 \%)$ five major meals and 12 (2.4\%) six meals. BMI status among the groups with various frequency of meals showed that frequencies of obesity and overweight increases with the frequency of meals (underweight vs. normal BMI. vs. overweight vs. obese: 3 meal/day $16.5 \%$ vs. $68.1 \%$ vs. $9.9 \%$ vs. $5.5 .1 \%$, 4 meal/day $11.7 \%$ vs. $65.7 \%$ vs. $11.7 \%$ vs. $10.9 \%$; 5 meal/ day $10.5 \%$ vs. $59.3 \%$ vs. $16.7 \%$ vs. $13.6 \%$ and 6 meals/day $33.3 \%$ vs. $41.7 \%$ vs. $8.3 \%$ vs. $16.7 \%\left(X^{2}=14.444, \mathrm{P}=0.107\right)$.

Overall $72.6 \%$ (366/504) children used to go to school on walking whereas the rest $(138 / 504,27.4 \%)$ used to go to their school in vehicles instead of walking. Number of subjects using vehicle and walking on foot were found to be $20.3 \%$ and $79.7 \%$ for underweight which were $24.1 \%$ and $75.9 \%$ for normal weight; $27.7 \%$ and $72.3 \%$ for overweight and $54.5 \%$ and $45.5 \%$ for obese respectively ( $X^{2} 2=23.795, \mathrm{P}<0.001$ ) (Figure 2).

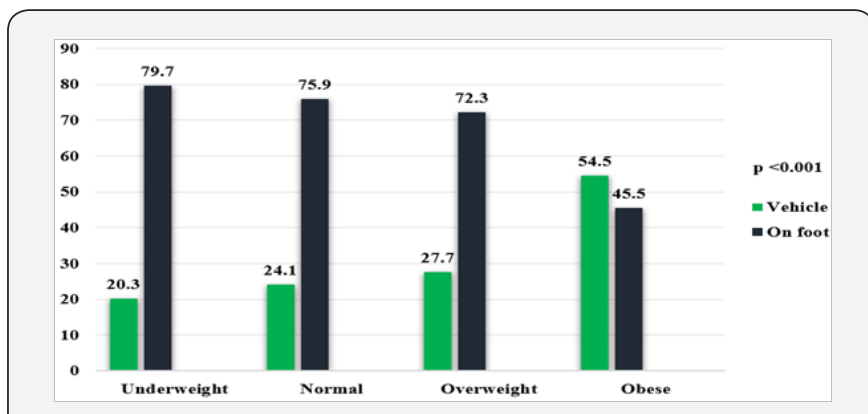

BMI: Body Mass Index; BMI calculated under reference cut-off value by Center for Disease Control (CDC); Underweight: BMI $<5^{\text {th }}$ percentile; Normal: $\mathrm{BMI} \geq 5^{\text {th }}$ to $<85^{\text {th }}$ percentile; Overweight: $\mathrm{BMI} \geq 85$ th to $<95$ th percentile; Obese: $\mathrm{BMI} \geq 95^{\text {th }}$ percentile

Figure 2: Use of vehicles (\%, over BMI subgroups) among various BMI groups

Table 3: Relation of BMI status with watching TV/playing games

\begin{tabular}{|c|c|c|c|c|c|}
\hline $\begin{array}{c}\text { Watch- } \\
\text { ing TV or } \\
\text { Playing } \\
\text { in Com- } \\
\text { puter } \\
\text { (Hours/ } \\
\text { Day) }\end{array}$ & $\begin{array}{c}\text { Under- } \\
\text { weight }\end{array}$ & Normal & $\begin{array}{c}\text { Over- } \\
\text { weight }\end{array}$ & Obese & Total \\
\hline 1 & $47(15.5)$ & $\begin{array}{c}196 \\
(64.5)\end{array}$ & $35(11.5)$ & $26(8.6)$ & 304 \\
\hline 2 & $10(7.0)$ & $90(62.9)$ & $21(14.7)$ & $22(15.4)$ & 143 \\
\hline 3 & $5(12.8)$ & $23(59.0)$ & $5(12.8)$ & $6(15.4)$ & 39 \\
\hline 4 & $2(11.1)$ & $11(61.1)$ & $4(22.2)$ & $1(5.6)$ & 18 \\
\hline Total & $64(12.7)$ & $\begin{array}{c}320 \\
(72.7)\end{array}$ & $65(12.9)$ & $55(10.9)$ & \\
\hline
\end{tabular}

(Within parenthesis are percentages over row total)

$X^{2}$ : 13.03; P: 0.158; BMI: Body Mass Index; Underweight: $\mathrm{BMI}<5$ th percentile; Normal: $\mathrm{BMI} \geq 5^{\text {th }}$ to $<85^{\text {th }}$ percentile; Overweight: $\mathrm{BMI} \geq 85^{\text {th }}$ to $<95^{\text {th }}$ percentile; Obese: $\mathrm{BMI} \geq 95^{\text {th }}$ percentile
In context to time spent for watching TV and playing games in computer per day, frequencies of underweight, normal, overweight and obese were for one hour: $15.5 \%, 64.5 \%, 11.5 \%$ and $8.6 \%$; for two hours:7.0\%, 62.9\%, $14.7 \%$ and $15.4 \%$; for three hours: $12.8 \%, 59.0 \%, 12.8 \%$ and $15.4 \%$ whereas for four hours: $11.1 \%, 61.1 \%, 22.2 \%$ and $5.6 \%\left(X^{2} 2=13.03, \mathrm{p}=0.158\right)$ (Table 3). Children who engaged themselves in outdoor games on an average about one hour per day had the frequency of obesity $10.5 \%$, overweight $13.8 \%$, normal BMI $64.2 \%$ and underweight $11.5 \%$, which were found to be $12.4 \%, 9.5 \%, 61.0 \%$ and $17.1 \%$ respectively for the children who spend $>1$ hour in outdoor games. $(\mathrm{p}=0.304)$ (Table 4).

Table 4: Relation of BMI status with playing outdoor games

\begin{tabular}{|c|c|c|c|c|c|}
\hline $\begin{array}{c}\text { Time } \\
\text { Spend in } \\
\text { Outdoor } \\
\text { Games } \\
\text { (Hours/ } \\
\text { Day) }\end{array}$ & $\begin{array}{c}\text { Under- } \\
\text { weight }\end{array}$ & Normal & $\begin{array}{c}\text { Over- } \\
\text { weight }\end{array}$ & Obese & Total \\
\hline $\begin{array}{c}1 \text { hour or } \\
\text { less }\end{array}$ & $46(11.5)$ & $\begin{array}{c}256 \\
(64.2)\end{array}$ & $55(13.8)$ & $42(10.5)$ & 399 \\
\hline$>1$ hour & $18(17.1)$ & $64(61.0)$ & $10(9.5)$ & $13(12.4)$ & 105 \\
\hline Total & $64(12.7)$ & $\begin{array}{c}320 \\
(63.5)\end{array}$ & $65(12.9)$ & $55(10.9)$ & 504 \\
\hline
\end{tabular}

(Within parenthesis are percentages over row total)

$X^{2}$ : 3.630; P: 0.304; BMI: Body Mass Index; Underweight: $\mathrm{BMI}<5^{\text {th }}$ percentile; Normal: $\mathrm{BMI} \geq 5^{\text {th }}$ to $<85^{\text {th }}$ percentile; Overweight: $\mathrm{BMI} \geq 85^{\text {th }}$ to $<95^{\text {th }}$ percentile; Obese: $\mathrm{BMI} \geq 95^{\text {th }}$ percentile

As expected, the socioeconomic condition $(\mathrm{r}=0.286, \mathrm{p}<0.001)$, the time spend for watching TV and playing computer games $(\mathrm{r}=0.131, \mathrm{p}=0.003)$ and use of vehicles $(\mathrm{r}=0.122, \mathrm{p}=0.006)$ positively correlated with BMI. Neither the time spent in outdoor games ( $\mathrm{r}=-0.015, \mathrm{p}=0.743)$ nor the frequency of meals $(\mathrm{r}=0.040$, $\mathrm{p}=0.370$ ) showed any correlation (Table 5).

Table 5: Correlations between different variables under study (Pearson or Spearman)

\begin{tabular}{|c|c|c|}
\hline Variables & $\mathbf{r}$ & $\mathbf{p}$ \\
\hline $\begin{array}{c}\text { BMI vs. socio-eco- } \\
\text { nomic condition }\end{array}$ & 0.286 & $<0.001$ \\
\hline BMI vs. meals & 0.04 & 0.37 \\
\hline BMI vs. vehicles & 0.122 & 0.006 \\
\hline BMI vs. watching TV & 0.131 & 0.003 \\
\hline $\begin{array}{c}\text { BMI vs. outdoor } \\
\text { games }\end{array}$ & -0.015 & 0.743 \\
\hline
\end{tabular}

\section{BMI: Body Mass Index}

Multiple regression analysis for predictive capability of different variables over obese BMI status revealed socio-economic condition $(p=0.007)$ and use of vehicle while going to school $(p=0.005)$ were independent predictors of obesity (Table 6). 


\section{Current Research in Diabetes \& Obesity Journal}

Table 6: Multiple regressions analysis of different variables for BMI $\left(>95^{\text {th }}\right.$ Percentile)

\begin{tabular}{|c|c|c|c|}
\hline Variables & B & SE & $\mathbf{p}$ \\
\hline Constant & -2.478 & 1.019 & 0.015 \\
\hline $\begin{array}{c}\text { BMI vs. so- } \\
\text { cio-economic } \\
\text { condition }\end{array}$ & 0.668 & 0.246 & 0.007 \\
\hline BMI vs. meals & 0.234 & 0.208 & 0.26 \\
\hline BMI vs. vehicles & 0.91 & 0.324 & 0.005 \\
\hline $\begin{array}{c}\text { BMI vs. watch- } \\
\text { ing TV }\end{array}$ & -0.007 & 0.182 & 0.968 \\
\hline $\begin{array}{c}\text { BMI vs. outdoor } \\
\text { games }\end{array}$ & -0.054 & 0.357 & 0.88 \\
\hline
\end{tabular}

BMI: Body Mass Index

\section{Discussion}

Childhood obesity has recently been an important concern worldwide and seems to play significant role in the development of many childhood diseases. We have also observed that childhood obesity among school going children of Bangladesh was increased than it is assumed [15]. In attempt to explore the contributing factors for childhood obesity an school going children the present study addressed investigation on socio-economic status, indoor entertainments and outdoor games enjoyed by the children, as well as frequency of meal intake and use of vehicles. It was observed that high socio-economic status and use of vehicles for school going were significantly related to obesity among the studied children while more engagement in sedentary entertainments but less with outdoor games as well as increased frequency of food intake imposed a positive influence on childhood obesity though not significant in this study.

Emerging problem of childhood obesity is being given high importance not only in developed but also in developing countries. Rapid social and lifestyle changes have led to this global epidemic imposing health related risk in the children resulting in increment of economic burden related to health. Bangladesh is considered a developing country. Therefore, it is at the stage of transition and changes in the socio-economic aspect, nutrition, food habits, culture and entertainments which are also equally implemented for the children. These shifts are largely associated with behavioral changes in dietary profile, lifestyle and decreased indulgence in physical activity. The socioeconomic status has got considerable impact on BMI of children that was also revealed by the present study.

The frequency of obese and overweight children were higher in high and middle socioeconomic class and the frequency of underweight was more in low and middle socioeconomic class, it was in keeping with other observations as well $[16,17]$. Researchers used family income as a primary indicator of socioeconomic status. In developed countries such as the UK, an association between low socio-economic condition and childhood obesity was strong [18]. On the contrary, in our country low socio-economic condition resulted in lower BMI among the children. This difference may be due to the fact that criteria of social deprivation vary in developed and developing countries. Social deprivation results in unavailability of sufficient food and thus causes nutritional deficiencies in developing countries. In developed countries, calorie dense foods from fast food outlets offer cheaper options for the children and working parents. However, in developing countries the opposite is true. These options are beyond the reach of people of lower socioeconomic strata.

One possible explanation for the different socioeconomic status over overweight and obesity in developing countries is the presumed influence of socioeconomic factors on people's lifestyles such as diet, food consumption patterns, and public services such as health care and transportation and physical activity. Richer people have better access to meat and other energy-dense foods (which are much more expensive than other foods such as vegetables) than the poor. In this study we correlated the number of meals consumed each day with the level of BMI and it was observed that frequency of obese and overweight was more in those who consumed four to five meals per day though it failed to reveal any statistically significant correlation. The probable reason for this discrepant finding might be that we only considered the number of meals consumed rather than emphasizing on the nature and the calorie content of the given meals.

Sedentary behavior and lack of physical activity in children may be predictive of BMI in studied children. Decreased sports and exercise have been implicated in childhood obesity because they reduce resting metabolism resulting from reduction of physical activity. A change in the volume of daily physical activity may account for imbalance between energy intake and energy expenditure. Physical inactivity among children has been related to obesity through different mechanisms. In the present study, increased level of physical activity in childhood attenuated BMI.

These findings are consistent with studies which observed that BMI in children is influenced by decreased outdoor activities and increased sedentary entertainments. In the present study it was found that obesity and overweight have inverse relationship with physical activity and those children who walked on foot to school had lower BMI than those who used vehicle for the same purpose. These data are consistent with previous studies in different countries [19].

Furthermore, it suggests that decrease in physical activity in daily living and at is work leads to less energy expenditure that directly contributes to weight gain in children. Thus, an active lifestyle during childhood like provision of playground in school, daily physical exercise can play an important role in optimizing growth and development. Comprehensive school and community programs need to be developed to promote physical activity among children [20]. Public awareness regarding healthy eating habits like avoidance of energy dense fast food, consumption of 
unprocessed, raw fruits and vegetables along with emphasis on regular physical exercise and curtaining sedentary entertainments needs to be created with active involvement of the social media, school authority and community leaders.

\section{Conclusion}

In conclusion, more use of vehicles instead of walking for going to school as well as high socioeconomic condition may be important contributing factors for child hood obesity in Bangladesh in addition to other factors. Concerned authorities should bring these factors into account for prevention of childhood obesity..

\section{References}

1. World Health Organization (2005) Preventing chronic diseases: A vital investment. World Global Report. Geneva, UK.

2. Raj M, Krishna R (2010) Obesity in children \& adolescents. Indian J Med Res 132: 598-607.

3. Ahmadi A, Gharipour M, Nouri F, Kelishadi R, Sadeghi M, et al. (2014) Association between adolescence obesity and metabolic syndrome: evidence from Isfahan healthy heart program. Indian J Endocr Metab 18(4): 569-573.

4. Economic Research Service Report (1999) Nutrient contribution of food away from home: America's eating habits: Changes and consequences. Agriculture Information Bulletin 750: 213-239.

5. Pereira MA, Kartashov AI, Ebbeling CB, Van Horn L, Slattery ML, et al. (2005) Fast-food habits, weight gain, and insulin resistance (the CARDIA study):15-year prospective analysis. Lancet 365(9453): 3642.

6. Smiciklas-Wright H, Mitchell DC, Mickle SJ, Goldman JD, Cook A (2003) Foods commonly eaten in the United States, 1989-1991 and 19941996: are portion sizes changing? J Am Diet Assoc 103(1): 41-47.

7. Young LR, Nestle M (2002) The contribution of expanding portion sizes to the US obesity epidemic. Am J Public Health 92(2): 246-249.

8. Poppitt SD, Prentice AM (1996) Energy density and its role in the control of food intake: evidence from metabolic and community studies. Appetite 26(2): 153-174.

9. Ledikwe JH, Rolls BJ, Smiciklas-Wright H, Mitchell DC, Ard JD, et al. (2007) Reductions in dietary energy density are associated with weight loss in overweight and obese participants in the PREMIER trial. Am J Clin Nutr 85: 1212-1221.

10. Ludwig DS, Peterson KE, Gortmaker SL (2001) Relation between consumption of sugar-sweetened drinks and childhood obesity: a prospective,observational analysis. Lancet 357(9255): 505-508.

11. Ebbeling CB, Feldman HA, Osganian SK, Chowmitz VR, Ellenbogen SJ, et al. (2006) Effects of decreasing sugar-sweetened beverage consumption on body weight in adolescents: a randomized, controlled pilot study. Pediatrics 117(3): 673-680.

12. Gortmaker SL, Must A, Sobol AM, Peterson K, Colditz GA (1996) Television viewing as a cause of increasing obesity among children in the United States, 1986-1990. Arch Pediatr Adolesc Med 150(4): 356362.

13. Robinson TN (1999) Reducing children's television viewing to prevent obesity: a randomized controlled trial. JAMA 282(16): 1561-1567.

14. Epstein LH, Saelens BE (2000) Behavioral economics of obesity: food intake and energy expenditure. In: Bickel WK, Vuchinich RE, (Edt.), Reframing health behavior change with behavioral economics. Lawrence Erlbaum Associates, Mahwah, NJ, USA.

15. BK-Rauniyar, Sharmin-Jahan, Nusrat-Sultana, Mashfiqul-Hasan, Atiqur-Rahman M, et al. (2018) Prevalence of obesity is rising among primary school children in Dhaka city of Bangladesh. Diabetes Obes Int J 3(3): 000182.

16. Ramesh K, Vitthaldas N, Banshi D, Phatak SR, Shah NN, et al. (2010) Prevalence of overweight and obesity in Indian adolescent school going children. its relationship with socioeconomic status and associated lifestyle factors. JAPI 58: 151-158.

17. Nazeem, Siddiqui I, Bose S (2012) Prevalence and trends of obesity in Indian school children of different socioeconomic class. Indian Journal of Basic \& Applied Medical Research 2: 393-398.

18. Conrad D, Capewell S (2012) Associations between deprivation and rates of childhood overweight and obesity in England, 2007-2010: an ecological study. BMJ Open 2: e000463.

19. Hills AP, Andersen LB, Byrne NM (2011) Physical activity and obesity in children. British Journal of Sports Medicine 45(11): 866-870.

20. Alok P, Malay P, Divyeshkumar V (2012) Prevalence of overweight and obesity in adolescents of urban and rural area of Surat, Gujarat. National journal of medical research 2: 325-329.

\begin{tabular}{|l|}
\hline \multicolumn{1}{|c|}{ Your next submission with Juniper Publishers } \\
will reach you the below assets \\
- Quality Editorial service \\
- Swift Peer Review \\
- Reprints availability \\
- E-prints Service \\
- Manuscript Podcast for convenient understanding \\
- Global attainment for your research \\
- Manuscript accessibility in different formats \\
( Pdf, E-pub, Full Text, Audio) \\
- Unceasing customer service \\
Track the below URL for one-step submission \\
https://juniperpublishers.com/online-submission.php \\
\hline
\end{tabular}

